Cite:

Prestridge, S. \& Cox, D. (2021) Play like a team in teams: A typology of online cognitive-social learning engagement. Active Learning in Higher Education, 1-18. Online first.

\title{
Play like a team in Teams: A typology of online cognitive-social learning engagement
}

Sarah Prestridge and Deniese Cox

\section{Biographical/contact details of authors}

Sarah Prestridge. Griffith University, Nathan Campus, Nathan 4111, Australia. Email address: s.prestridge@griffith.edu.au; https://orcid.org/0000-0002-7873-1538

Sarah Prestridge is a senior researcher within the Griffith Institute of Educational research, Griffith University Australia. She investigates the nexus between digital pedagogies, epistemology and professional learning. In drawing these three areas together, her research examines how to change teaching practices; how professionals learn online; and the current shift to flexible remote education.

Deniese Cox. Griffith University, Australia. Email address: deniese.cox@griffith.edu.au https://orcid.org/0000-0003-0365-706X

Deniese Cox has been teaching online for many years in both higher and vocational education sectors. She is a sought-after mentor, helping teams from a variety of institutions to achieve better online experiences for all involved. Deniese's research interests are on the gap between enacted online practice and what individual educators perceive as ideal.

\begin{abstract}
Within higher education, students and institutions are increasingly moving toward blended components and fully online learning coursework. Best practice online pedagogy is understood to be student-centred with a strong emphasis on social learning through collaboration. The social aspect supports frequency of engagement while collaborative activity supports cognitive engagement. Research that guides online pedagogy draws substantially from studies identifying type and frequency of students' cognitive engagement, usually along a continuum but without the nuance of social learning. To build on that and to identify profiles of cognitive-social engagement, this study examined the content of 3,855 student posts from one course within a chat-based platform. The findings suggested six student engagement types: lurk, superficial, task, respond, expand, create. These types were then further examined along two continuums of complexity and intensity of engagement. The results present a new typology of cognitive-social learning engagement defined by four profiles: bench sitter, hustler, striker, champion. The typology was purposely fashioned using team-play acronyms to build a useable language for educators to recognise student engagement profiles and to guide learning design in social spaces online.
\end{abstract}

Keywords: community of inquiry, learner profiles, online course, discussion forum.

\section{Teaching online for student engagement}

University students are required to transition from school-based regulated learning to open, empty platforms in which engagement with content and engagement with their peers matters. Engaging with peers online is different from engaging with peers face-to-face, and course design as well as instructional practices are different between face-to-face and online classrooms. Both institutions and their students are demanding flexible modes of coursework which has evidenced a considerable shift toward teaching and learning that is blended or fully online (Adekola et al., 2017). Teaching online is different to teaching on campus, and the move towards online delivery has implications for every aspect of course design including the changing role of the teacher and the student (Rodrigues et al., 2019). 
Teaching digitally is more than simply knowing how to use technology or transferring materials to an online platform (Palloff and Pratt, 2013), it requires different pedagogies and new ways of engaging and communicating with students (Jensen et al., 2019; Philipsen et al., 2019; Rodrigues et al., 2019). Furthermore, teaching online is not instinctive for many (Yen et al., 2018). The problem of shifting online has been identified as relating to the dichotomy between how to use digital tools for course delivery in relation to how students use digital tools for engagement practices (Ellis and Bliuc, 2019).

With regard to how to use digital tools, best-practice online pedagogy has been understood to be student-centred theoretically (Trinidad, 2019). Yet a systematic review revealed that educators still generally lack effective and detailed means to design student-centred delivery methods (Sun and Chen, 2016). This disparity relates to a current predicament that educators are grappling with, which is, not knowing how to engineer meaningful student engagement within online coursework. If we want to guide effective online pedagogy in course design we first need to understand how students are engaging as part of a student-centred online learning system.

One of the most frequently utilised models for understanding both teaching and student engagement online is the community of inquiry model (Akyol and Garrison, 2011; Annand, 2011; Rourke and Kanuka, 2009; Garrison et al., 2000). The model predicates the interplay of three elements: teaching, cognition and socialization based on a large body of empirical evidence underpinning online learning design for student interaction, information seeking, and knowledge building (Garrison et al., 2010). Previously the model has been applied to student engagement types within the community of inquiry using one digital tool, such as the asynchronous discussion forum, as well as with a whole online course utilizing many digital tools. However, when examining student engagement practices online, the community of inquiry model has been used to conceptualise student engagement divorce of the interplay of the three elements, with a significant focus on cognition through quantitative measures (see Kovanović et al., 2015; Rubin et al., 2013).

The examination of student engagement types within online course work and specifically within asynchronous online discussion forums has been examined (Chen et al., 2020; Bliuc et al., 2010; Lust et al., 2013; Yen and Lee, 2011; Yen et al., 2018). For example, students were clustered into six different profiles in the Kovanović et al. (2015) study of cognitive presence in online discussion forums: 1) taskfocused users, 2) content-focused no-users, 3) no-users, 4) highly intensive users, 5) content-focused intensive users, and 6) socially-focused intensive users. These were based on counts of task activity and time spent on tasks. High cognition was evidenced by task focused-user activity, high amounts of time was attributed to three students only as highly intensive-users, while the largest student profile was no-users. This study did not account for social presence or build more nuanced profiling based on actual content of posts. In a similar approach, Lust et al. (2013) used frequency measures and a Likert scale questionnaire to examine students' use of digital tools in a learning management system in a blended course. Four student profiles were found: 1) No-user (43\%); 2) Selective-users of on-campus tools such as lectures (32\%); 3) Intensive-active user (10\%) and; 4) Intensive-selective user (15\%). In line with the Kovanović et al. profiles and Lust's research, only a minority of students were using digital tools for meaningful learning (Lust et al., 2012).

Rather than profiling activity, Bliuc et al., (2010) examined engagement types along two relational continuums to examine the content of student engagement while using an online digital forum. They found a 'cohesive conception-deep approach' where students conceived discussions as a learning process compared with a 'fragmented conception-surface approach' where students believed that discussions serve as a way to improve skills or to get an answer. The findings of this study called to examine in more depth these two distinct groups of students and what could be considered meaningful learning using online discussion forums. With regard to developing further understanding of what is meaningful in student online discussions, Yen and Lee (2011) used cluster and content analysis finding three student profiles for problem solving in a blended learning context. These were the 'hybrid-oriented' group, which was over half the participants, who followed a procedural passive approach; the 'technology-oriented' group who were active online but superficial in problem-solving; and the 'efficiency-oriented' group (14\%) who used the technology to advantage a more advanced problem solving process. These findings align with the studies on student profiles presented previously, which supports the idea that students who are cognitively active remain low in number, often the smallest within the given cohorts. 
In the online environment as in any other, there are differences between students in terms of how they engage. Some engage only at a superficial level whereas others engage fully. In an online learning community, there are those who are driven to contribute to the co-construction of new knowledge. Coconstruction of knowledge, such as responding, expanding, and creating ideas, indicates a more complex level of cognition than simply receiving ideas and/or resources. These engagement processes contribute to a learning community and this is important because learning communities have long been understood as essential for learning online (Garber, 2004). However, development of such a community requires students to be self-motivated, independent, self-confident, skilled collaborators to successfully work collaboratively in online platforms, yet many of them are unlikely to be ready to do so (Shea and Temi, 2010; Ifenthaler, 2012). To support student engagement in online communities, Bain (2004) directed instructors to be learning engineers, "engaging students [and] engineering an environment in which [students] learn" (p. 49). The idea of a 'learning engineer' moves away from the teacher-centric mode in course design and delivery and even beyond the facilitator mode, to the teacher taking a more heightened in-situ role in the repurposing of an on-going task responsive to student interactions and needs, as well as engineering activities that increase student-to-student engagement (Donald et al., 2009; Svihla et al., 2015).

In summary, the picture evidences a small cluster of students engaging in complex cognition at the end of the learning continuum within online components in courses. There is therefore a need for a more nuanced understanding of meaningful learning in online discussion forums. There is also a disconnect between the complexity of engagement and learning within the community of inquiry where the social, the cognitive, and the pedagogical approaches are interdependent and as such need to be examined in relation to each other over a sufficiently long period of time. This study is therefore guided by the central question: How do students engage cognitively across a socially constructed chat-based environment?

\section{Research methods}

The use of Gunawardena et al.'s (1997) interaction analysis model is adopted as a conceptual framework. Knowledge construction, as espoused by this model, is related to online sharing and negotiation represented by five phases: 1) comparing information; 2) discovering inconsistency; 3 ) negotiating ideas; 4) testing of co-construction with evidence, and 5) agreement statements or application of new idea. To ensure a mutual focus on social presence as depicted in the community of inquiry model, Chi and Wylie's (2014) ICAP framework for interactive learning was used. This framework builds on active and constructive engagement to operationalise interactive online dialogue to be: a) conversational posts between two or more people that is constructive, ideas extend beyond given concepts; and b) there is a sufficient degree of turn taking. These social interactions can be described as defending or arguing, seeking justification, asking and answering questions, explaining and elaborating on each other's contributions, and these are posts that are more likely to receive responses and to support greater opportunity for socially-mediated cognition (Chen et al., 2020). Chi and Menekse (2015) describe these social learning interactions as joint dialogue in which both participants benefit compared to individual dialogue where learning evolves only for the dominant speaker.

The course investigated was considered a single case (Willis, 2007) using an interpretivist stance that positioned the actions of students in the creation of their social reality bounded within a specific time and space (Thanh and Thanh, 2015). As such, this study was positioned as a qualitative study supported by quantitative methodologies. This case study focused solely on students' posts in Microsoft Teams which was the digital tool used to facilitate asynchronous student discussion within the course. The investigation involved a sequential exploratory design in three stages in which both qualitative and quantitative methods were used interactively. To drill down into the data, stage one was used to gain a general understanding of the amount of activity and broad engagement types. The second stage categorised engagement types, while the third stage used these categories to further examine students' posts through a typology based along two continuums of cognitive complexity and intensity (Ivankova et al., 2006).

\section{Case course context and design}

A 12-week undergraduate course was facilitated for the first time in 2019 with 181 student across three geographically separate campuses. The two authors were part of the teaching team. Two digital 
platforms were utilised for course facilitation. The university's chosen LMS is Blackboard $\odot$, and Microsoft Teams (hereafter referred to as Teams) had been recently introduced and was in trial phase. Teams as an environment is purposefully collaborative utilising a social, chat-based style of interaction between users (Balu, 2018) as such the teaching team viewed it as an opportunity to create commuity amongst the cohort. Based on the findings of both Ellis and Bliuc (2019) and Riehemann et al. (2018) on the need for purposeful and modelled integration of online learning technologies, the course design was such that students would access both Teams and Blackboard platforms at different times for different purposes (see Figure 1 as the predicted design for course engagement activities). The LMS was used as a traditional course site whereby students could receive resources and lodge completed assessment tasks while Teams was integrated as the platform to facilitate student participation and interactivity.

$<<$ insert figure 1 here >>

The course was about the development of students' use of information and communication technologies in education. The first of two 6-week modules was facilitated using a standard on-campus teaching model with a weekly 2-hour lecture plus 1-hour tutorials at each campus. Teams was used during oncampus tutorials using tasks such as reflecting on and discussing course readings, and crowd-sourcing ideas that students could incorporate into their assessment task.

In Module 2 the course focused on developing students' professional learning networks to prepare them for self-directed professional development after graduation. This module was facilitated wholly online and featured a set of five learning topics which students were expected to work through at their own pace (see Table 1).

$<<$ insert table 1 >>

Each topic included instructional videos, written content, and suggested tasks for students to individually complete. Students were expected to use Teams to share their tasks and learnings with peers. Tasks included reflecting on content, generating mind maps, sharing ideas through non-serious memes, creating inspirational posters, setting professional goals, and creating new connections with experienced educators through social media. The teaching team did not start new discussions for students. Rather, they had a minor role of responding encouragingly to student-led discussions, observations, and statements. The assessment item for this module required students to write a reflective essay. It is important to note that student grades or marks were not linked to Teams participation or on completion of those tasks.

Data collection and analysis

All student and teaching team posts were considered data derived from what Sharpe (2006) described as "a more appropriate moment to an individual" (p. 16), that is, when the students chose to post. We examined the content of each individual post and examined interchanges between students. Simple frequency analysis was used to identify and understand patterns of engagement. We combined the five phases of knowledge construction (Gunawardena et al.'s model, 2016: 37) with the two criteria for interactive online dialogue (ICAP framework), as can be seen in Table 2.

$<<$ insert table 2 here >>

An inductive thematic analysis of the content of student's posts occurred separately for Module 1 and Module 2. In Module 1, the two researchers manually reviewed the content of 281 posts to develop inductive codes, categorise posts to these codes, and count the number of posts per category. This review incorporated the thematic process of broadly examining, comparing, conceptualising, and categorising data (Strauss and Corbin, 1998). In Module 2, the two researchers manually reviewed the content of 3,574 individual posts and then examined the interactions between posts using screen grabs. The analytical framework was used to guide the researchers to ask questions of the data and the 
thematic coding of categories. The process involved the two researchers individually coding a random selection of posts within both course modules. The coded units were then compared in order to discuss disagreements, refine categories, and define a shared coding scheme. The resulting defined categories were decoded from analysis of student posts and then encoded to all student posts (Flick et al., 2004; Saldana, 2016). An Excel spreadsheet was used to manually record every post by its type. Data was recorded for each the five learning topics and then cumulatively. Lastly, the researchers each chose a weekly learning topic, using a screenshot of each occurrence of interaction where there was either oneto-one student interaction or one-to-many student interactions. Codes were assigned to identify the types of interactive dialogue. Coding and recording were discussed between the researchers to safeguard the quality and consistency of interpreted data. All disagreements and interpretations were resolved through discussion. Patterns and differences across posts were reviewed through constant comparisons, and development of categories enabled simple frequency analysis to then occur. Student names have been de-identified in accordance with ethical protocols.

\section{Findings}

In Module 1 three broad categories of student engagement were evident. These categories were: 1) background participation, 2) engaging with content, and 3) generating content. Background participation included posts where the student introduced themselves, asked routine questions about the course, clarified assessment expectations, were matched in assessment pairs, or agreed with another student's post; $67.4 \%$ of students enrolled in the course made background posts. Engaging with content posts included reflecting on and discussing assigned readings or key learnings from lectures; $39.8 \%$ of students engaged with content. Generating content posts included proactively crowd-sourcing digital tools appropriate for the graded assessment task that students were building toward; $12.2 \%$ of students generated content. Table 3 presents, by type and number of posts, how many of the 181 students engaged.

$<<$ insert table 3 here >>

Figure 2 illustrates a typical example of students generating content. The utilisation of Teams' @Mentions facility (Balu, 2018) to get the attention of a particular peer enhanced the conversational nature of student interactions.

$<<$ insert figure 2 here>>

In summary, $124(68.5 \%)$ students chose to use Teams in some form. This period of engagement enabled students to build familiarity with the platform and with social learning in a chat-based environment ahead of the wholly online second module. At the time of this study, Teams and online components were new learning experiences for most of the students.

In Module 2, 176 of the 181 students (97.2\%) actively engaged through Teams. Those active students made 3,574 posts. Six data-driven categories emerged to represent the complexity of engagement, and these categories were then quantitatively applied to the data by student and by learning topic. Those six categories of cognitive-social engagement were: lurk, superficial, task, respond, expand, and create, and they are described in Table 4.

<<insert table 4 here>>

A second stage of analysis sought to understand complexity of engagement and how cognitive-social engagement changed or developed across the five learning topics. Figure 3 presents a side-by-side comparison of the number of students (left) and the number of engagements (right) across the five topics along with the underpinning engagement types (see Table 5). 
$<<$ insert figure 3 here>>

$<<$ insert table 5 here >>

The first engagement type, lurk, was considered inactive engagement. This type represents students who did not actively engage with that topic. The number of students who lurked grew from $6.6 \%$ in Topic 1 to $29.8 \%$ in Topic 5 . The second engagement type, superficial, was considered low cognitive engagement. This type represents students who liked another student's post and did so through a social emoji such as thumbs up, smile, or heart, or who wrote a short phrase such as 'I agree'. The number of students and the frequency of this engagement type fluctuated across the five topics. The 141 $(77.9 \%)$ students who made superficial posts ranged from one to 62 posts of this type, with a mean of 7.7.

The third engagement type, task, was the most prevalent type of engagement $-93.4 \%$ of students engaged this way and $44.9 \%$ of total engagements across the five learning topics were categorised as task. Notably, the number of students engaging by task peaked at the start of the course with a steady decline thereafter. The highest mean task engagement was for Topic 1 where there were three suggested tasks for students to each complete - a mean of 2.6 was observed across 163 students. This is followed by Topic 2 where there were four suggested tasks and a mean of 2.7 was observed across 157 students. The mean then dropped to 2.2 for Topic 3 ( $79.0 \%$ students), 1.6 for Topic 4 ( $76.8 \%$ students), and 1.8 for Topic 5 (63.0\% students).

Students moving beyond doing the learning task to deeper cognitive engagement is represented by the categories of respond, expand, and create. The respond engagement type fluctuated across topics for both numbers of students and numbers of engagements. Although students did not post all of the 16 suggested tasks across the five topics, mean task engagement could be considered high at 9.5 overall. The number of students engaging as respond peaked during Topic $1(48.6 \%)$ and Topic $4(47.5 \%)$. The number of engagements by this type peaked during Topic 5 with students making multiple (mean 2.4) contributing responses to their peers. Figure 4 exemplifies respond engagement and features students Name 2, Name 3, and Name 4 each responding to and acknowledging Name 1's contribution. This is an important example because it exemplifies 'more than' superficial engagement in two ways. First, students are 'more than' posting a one-directional, static post. Instead they are conversationally responding to each other. Second, responses are 'more than' simple agreement statements and are instead students making sense of the learning topic by conversing about each other's contributions.

$<<$ insert figure 4 here >>

The next engagement type, expand, increased in frequency as the topics progressed although remained low when compared to other less cognitively complex engagement types. Across the five topics, $78(43.1 \%)$ students engaged this way although the number of these engagements represented only $5.5 \%$ of total engagements. This engagement type represented students expanding on a peer's task post with statements in which ideas were developed or clarified, or extension of a concept was evident. As illustrated in Figure 5, Name 2 and Name 3 expanded on Name 1's contribution. Name 1 drew a relationship to her own experiences, confidence, and outcomes, while Name 2 extended the ideas being discussed. Again, this is an example of 'more than' superficial engagement and represents the conversational interaction between students that deepens learning.

$<<$ insert figure 5 here>>

The final engagement type, create, was observed twice - once by a student during Topic 2 and later by a different student during Topic 4 . The create type post during Topic 2 generated extensive respond engagement by other students as they worked together to crowd-source the names and handles of perceived quality educators on Instagram. A create type post made by a student during Topic 4 
encouraged peers to proactively follow each other on social media, thereby creating a long-term professional network that would endure beyond graduation.

In summary, during Module 2, six categories of student engagement were identified - one inactive engagement and five active engagement types - with these representing increasing cognitive complexity. Task was the most prominent engagement type and superficial engagement was evident throughout at fluctuating rates. More cognitively complex engagement was observed throughout all five topics, but at lower frequencies. Students contributing a new idea above and beyond the assigned tasks was only evident twice. Notably, the nature of engagement between students in this platform was social and chat-based and utilised features of Teams such as @Mentions to get the attention of particular peers.

\section{A typology of online cognitive-social learning engagement}

The five types of active engagement described above provide a way of representing the different ways students engaged through a social chat in an online forum. What those engagements types did not adequately convey is a deeper examination of how, when, and how-often students individually enacted different engagement types. To yield such understanding, all student posts were re-examined along two continuums of complexity and intensity, and a typology of online cognitive-social learning engagement emerged. As illustrated in Figure 6, along the complexity axiom, labels of lurk and superficial engagement was low complexity, task engagement was low-medium complexity, respond engagement was medium-high complexity, and expand and create engagement was high complexity. Along the intensity axiom, zero to 9 engagements was categorised as low intensity, 10 to 19 engagements as low-medium intensity, 20 to 29 engagements as medium-high intensity, and more than 30 engagements as high intensity. The resulting four quadrants were labelled to represent engagement approaches here as bench sitter, hustler, striker, and champion. The adaptation of sporting terms was intended to help future users easily distinguish between the different approaches students adopt as they engage in online cognitive-social learning.

$<<$ insert figure 6 here>>

The features of each of the four online student engagement profiles are now described starting with the first approach, bench sitter. The bench sitter is the most basic type of online cognitive-social learning in this chat-based environment. It represents a student who does not post frequently or with much complexity. A student with this profile might 'like' or 'agree' with a few other posts, and not contribute new information beyond occasionally posting a completed task.

Next is the hustler profile. The hustler student engages with high intensity, that is, frequently posting, but their posts have low complexity. An example student with this profile is one who frequently gives a 'thumbs up' to other posts while also posting their own completed tasks, but not engaging in meaningful chats with other students.

The third of four profiles is striker. Striker students are those who engage with high complexity but low intensity. Put simply, while they may not engage often within the chat-based platform, when they do engage their post is often complex and thought-provoking. They typically contribute new, interesting observations when responding to other posts, and might expand on the concepts at hand.

Finally, the champion engagement profile represents students who engage proactively by contributing their own task posts while also building on other students' engagement. These students demonstrate high complexity and high intensity engagement, and are a leader in the online community by frequently using all engagement types.

It was observed that students with a champion profile completed most of the expected tasks and regularly returned to the learning space to respond to and expand on contributions made by other students. Champion students sought to explore the learning topic ideas more deeply, to extend their peers' thinking, and to make suggestions that actively supported peers. Their engagement was for the good of the learning community. As exemplified in Figure 7, Name 1 was one such student. Her post went beyond the scope of the course task, asking for contributions from peers to extend every student's 
professional network. Name 1 returned 11 days later to provide a peer with a link to this chat thereby further connecting and encouraging another student's learning.

<<insert figure 7 here>>

Drawing on data that reflected frequency and type of engagement, an examination of each of the 181 students was profiled. The results are illustrated in Figure 8 . On the left, the number and percent of students for each profile is presented. On the right, the number of students for each profile (blue) and the underpinning sub-quadrants within each profile (yellow) is presented.

$<<$ insert figure 8 here >>

Of the 59 students with a bench sitter profile, only 9 students were in the sub-quadrant of low intensity and low complexity. In contrast, 20 students were in the low-medium complexity and intensity subquadrant which indicates their participation was generally task in nature. Within the hustler profile, 18 of 58 students were in the high intensity, low-medium complexity sub-quadrant. Participation for these students was also task-focused but occurred more frequently and therefore is represented here as higher intensity. The striker profile includes 37 students. Of those, 20 were in the medium-high complexity and low intensity sub-quadrant. These students were those who did not participate often, but when they did it was to respond to another post, sharing their own perceptions and/or asking clarifying questions. The final profile, champion, was found to have 37 students. Of these, 19 engaged with medium-high complexity and intensity. These students were those who also responded by sharing their own perceptions or asking clarifying questions, and who did so frequently.

\section{Discussion with conclusions}

The main research question asked how students engage cognitively across a socially constructed chatbased environment. This investigation specifically pushed the examination beyond what is known as meaningful engagement to represent cognition within a chat-based platform. Six types of engagement that increase in cognitive complexity emerged. These are lurk, superficial, task, respond, expand, and create. These types and their descriptors could offer educators a language with which to design courses and interventions that encourage and facilitate the type of engagement desired over the delivery phase of a course.

The three engagement types with lower cognitive complexity (lurk, superficial, task) feature students simply 'liking/agreeing' using social emojis or completing assigned tasks. These engagements somewhat mimic teacher-centric pedagogy. The three engagement types with higher cognitive complexity (respond, expand, create) offer insights into how students process course content and engage with each other to extend and co-create knowledge. Leveraging the chat-based platform to facilitate students within an environment that is a community of inquiry was evidenced by students 'more than' simply liking, agreeing, or completing an assigned task. Differences in social reasoning were observed between the engagement types. In the first three types (lurk, superficial, task), students were engaging for themselves - liking, doing, watching. In the second three types (respond, expand, create), students were more community oriented and this was represented by extending each other's thinking over time. In other words, students enacted an active learning community (see de Laat et al., 2017; Lave and Wenger, 1991) and played like a team in Teams.

Different to complexity of engagement is engagement intensity, that is, with what frequency did individual students engage across the six identified engagement types. To integrate complexity and intensity, a new typology of cognitive-social learning is presented to the field. This typology frames students' participation in an online chat-based platform and represents engagement learning behaviours with four profiles: bench sitter, hustler, striker, and champion. These student profiles do not reflect the findings from studies in regard to the small percentage of students demonstrating complex learning cognition (Kovanović et al., 2015 and Lust et al., 2013). In the study described in this article both champions and strikers demonstrated complexity of engagement and were $40 \%$ of the cohort. The 
nuances of social learning and temporal patterns of engagement was able to provide a deeper picture of their approaches to learning.

Evident in the findings of this research is the move beyond that deficit model of online learning capabilities as determinants for more complex engagement types. What this research instead suggests is that if course design provides the relational student spaces, then students engaging with higher levels of intensity and complexity is related more to student choice to engage rather than their online learning skills.

The limitations are the following. Data was gathered only from undergraduates not postgraduates, only from one pathway within one discipline, and only from one university within one single country/cultural context. As student discussion may vary according to factors such as tertiary level, discipline, and culture, future studies into possible differences in terms of factors such as gender, discipline and culture are warranted. Engagement with, and development of content was deliberately separated from the LMS where students were used to simply receiving information and so it may be that discussion/engagement could be influenced by the medium itself, that is, the use of Teams may have prompted a particular type of dialogue, one that might be different in a discussion board. There is also an opportunity for a followup study to examine relationships between task type and engagement type given that this was not investigated.

The presented profiles of student engagement are intended to offer educators language with which to consider and plan course design. Furthermore, educators might utilise these understandings to reflect on engagement outcomes that result from different teaching interventions that they implement. For example, framing themselves as a coach or perhaps a cheerleader as suggested by Hung and Chou (2015), or being able to differentiate between the highly visible hustler student and the less visible but deeper contributing striker student may be useful. Associated with engagement types is the finding that the champion engagement type could be considered the most 'productive' or 'leading' type for online social learning. This may suggest a direction for individual educators on how to facilitate a move from bench sitter to champion amongst their student cohort. At its core, the typology for online cognitivesocial learning provides a language that could be used to discuss with students how they can engage, or are engaging, with course content and each other online and how to support a change in their behaviours toward a target engagement type.

The findings on types of student engagement and course design suggest three underlying implications important to online education research. These are engagement types in social learning, the student profile, and a way to cognitively improve social learning. Associated with engagement types and course design is the issue of student profiles. Using these defined profiles as a basis for further research would provide a deeper and much needed understanding of online course design features and the pedagogies related to effective online learning. Such studies could focus on examination of individual pathways across the delivery of online courses; the life-cycle of engagement such as from hustler to champion to striker in relation to course design and delivery; or a cognisant shift from bench sitter to champion. This would enable examination of relationships between course design features and engagement behaviours, and relationships between engagement behaviour and student achievement outcomes. However, further research is necessary before suggesting that such a developmental push toward a different engagement type would productively yield deep student learning outcomes and/or (adversely) affect the nature of learner communities.

Engaging with peers online is different from engaging with peers face-to-face, and course design as well as instructional practices are different between face-to-face and online classrooms. What this research contributes is an illustration of how students engage with other within online coursework through the incorporation of student-centred pedagogies. As Fullan (2003) described long ago, social interaction provides means for "convert[ing] information into knowledge" (p. 47) as long as people are encouraged to discover new truths, and that these truths and knowledges are being continually challenged. Supporting students to respond, extend, and create with each other, as well as becoming self-aware of how they are engaging, may lead to deeper learning. This research therefore lays foundations for further studies into online cognitive-social learning in chat-based platforms. Such research would extend our understanding of relationships between the intensity and complexity of student engagement, course design, and student outcomes. 


\section{References}

Adekola J, Dale VHM and Gardiner K (2017) Development of an institutional framework to guide transitions into enhanced blended learning in higher education. Research in Learning Technology 25: 1-16.

Akyol Z and Garrison DR (2011) Understanding cognitive presence in an online and blended community of inquiry: Assessing outcomes and processes for deep approaches to learning. British Journal of Educational Technology 42(2): 233-250.

Annand D (2011) Social presence within the community of inquiry framework. International Review of Research in Open \& Distance Learning 12(5): 40-56.

Bain K (2004) What the Best College Teachers Do, Cambridge, Mass: Harvard University Press.

Balu IN (2018) Introducing Microsoft Teams: Understanding the New Chat-Based Workspace in Office 365. New York: Apress.

Bliuc A-M, Ellis R, Goodyear P, et al. (2010) Learning through face-to-face and online discussions: Associations between students' conceptions, approaches and academic performance in political science. British Journal of Educational Technology 41(3): 512-524.

Chen G, Lo CK and Hu L (2020) Sustaining online academic discussions: Identifying the characteristics of messages that receive responses. Computers \& Education 156: 1-14.

Chi MTH and Menekse M (2015) Dialogue patterns in peer collaboration that promote learning. In: Resnick LB, Asterhan CSC and Clarke SN (eds) Socializing Intelligence Through Academic Talk and Dialogue. Washington, DC: AERA, 263-274.

Chi MTH and Wylie R (2014) The ICAP framework: Linking cognitive engagement to active learning outcomes. Educational Psychologist 49(4): 219-243.

de Laat M, Vrieling E and van den Beemt A (2017) Facilitation of social learning in teacher education: The 'dimensions of social learning framework'. In: McDonald $\mathrm{J}$ and Cater-Steel A (eds) Communities of Practice: Facilitating Social Learning in Higher Education. Springer, 153-174.

Donald C, Blake A, Girault I, et al. (2009) Approaches to learning design: past the head and the hands to the HEART of the matter. Distance Education 30(2): 179-199.

Ellis RA and Bliuc A-M (2019) Exploring new elements of the student approaches to learning framework: The role of online learning technologies in student learning. Active Learning in Higher Education 20(1): $11-24$

Flick U, von Kardorff E and Steinke I (2004) A Companion to Qualitative Research. London: SAGE Publications.

Fullan M (2003) Change Forces With A Vengeance, London: Routledge Falmer.

Garber D (2004) Growing virtual communities. International Review of Open and Distance Learning 5(2): 1-7.

Garrison DR, Anderson T and Archer W (2000) Critical inquiry in a text-based environment: Computer conferencing in higher education. The Internet and Higher Education 2(2-3): 87-105.

Garrison DR, Anderson T and Archer W (2010) The first decade of the community of inquiry framework: A retrospective. The Internet and Higher Education 13(1-2): 5-9.

Gunawardena CN, Flor NV, Gomez D, et al. (2016) Analyzing social construction of knowledge online by employing interaction analysis, learning analytics, and social network analysis. Quarterly Review of Distance Education 17(3): 35-60.

Gunawardena CN, Lowe CA and Anderson T (1997) Analysis of a global online debate and the development of an interaction analysis model for examining social construction of knowledge in computer conferencing. Journal of Educational Computing Research 17(4): 397-431.

Hung M-L and Chou C (2015) Students' perceptions of instructors' roles in blended and online learning environments: A comparative study. Computers \& Education 81: 315-325.

Ifenthaler D (2012) Determining the effectiveness of prompts for self-regulated learning in problemsolving scenarios. Journal of Educational Technology \& Society 15(1): 38-52.

Ivankova NV, Creswell JW and Stick SL (2006) Using mixed-methods sequential explanatory design: From theory to practice. Field Methods 18(1): 3-20.

Jensen L, Price L and Roxå T (2019) Seeing through the eyes of a teacher: Differences in perceptions of HE teaching in face-to-face and digital contexts. Studies in Higher Education(6): 1149-1159.

Joksimovic S, Gasevic D, Kovanovic V, et al. (2015) Social presence in online discussions as a process predictor of academic performance. Journal of Computer Assisted Learning 31(6): 638-654.

Kovanović V, Gašević D, Joksimović S, et al. (2015) Analytics of communities of inquiry: Effects of learning technology use on cognitive presence in asynchronous online discussions. The Internet and Higher Education 27: 74-89. 
Lave J and Wenger E (1991) Situated learning: Legitimate Peripheral Participation, Cambridge: Cambridge University Press.

Lust G, Elen J and Clarebout G (2013) Students' tool-use within a web enhanced course: Explanatory mechanisms of students' tool-use pattern. Computers in Human Behavior 29(5): 2013-2021.

Lust G, Juarez Collazo NA, Elen J, et al. (2012) Content Management Systems: Enriched learning opportunities for all? Computers in Human Behavior 28(3): 795-808.

Palloff RM and Pratt K (2013) Lessons from the Virtual Classroom: The Realities of Online Teaching, San Francisco: Jossey-Bass.

Philipsen B, Tondeur J, Pareja Roblin N, et al. (2019) Improving teacher professional development for online and blended learning: A systematic meta-aggregative review. Education Technology Research and Development 67: 1145-1174.

Riehemann J, Hellmann JH and Jucks R (2018) "Your words matter!" Relevance of individual participation in XMOOCs. Active Learning in Higher Education 22(1): 1-14.

Rodrigues $\mathrm{H}$, Almeida F, Figueiredo V, et al. (2019) Tracking e-learning through published papers: A systematic review. Computers \& Education 136: 87-98.

Rourke $\mathrm{L}$ and Kanuka $\mathrm{H}$ (2009) Learning in communities of inquiry: A review of the literature. Journal of Distance Education (Online) 23(1): 19-47.

Rubin B, Fernandes R and Avgerinou MD (2013) The effects of technology on the Community of Inquiry and satisfaction with online courses. The Internet and Higher Education 17(1): 48-57.

Saldana J. (2016) The Coding Manual for Qualitative Researchers, London: SAGE Publications Ltd.

Sharpe B (2006) The ambient web. In: BETCA (ed) Emerging Technologies for Learning. Coventry, UK: British Educational Communications and Technology Agency, 16-31.

Shea P and Temi B. (2010) Learning presence: Towards a theory of self-efficacy, self-regulation, and the development of a communities of inquiry in online and blended learning environments. Computers \& Education 55(4): 1721-1731.

Strauss A and Corbin J (1998) Basics of Qualitative Research: Techniques and Procedures for Developing Grounded Theory, California: SAGE Publications.

Sun A and Chen X (2016) Online education and its effective practice: A research review. Journal of Information Technology Education: Research 15: 157-190.

Svihla V, Reeve R, Sagy O, et al. (2015) A fingerprint pattern of supports for teachers' designing of technology-enhanced learning. Instructional Science 43(2): 283-307.

Thanh NC and Thanh TTL (2015) The interconnection between interpretivist paradigm and qualitative methods in education. American Journal of Educational Science 1(2): 24-27.

Trinidad JE (2019) Understanding student-centred learning in higher education: students' and teachers' perceptions, challenges, and cognitive gaps. Journal of Further and Higher Education 44(8): 1-11.

Willis JW. (2007) Foundations of Qualitative Research: Interpretive and Critical Approaches, California: SAGE Publications.

Yen J-C and Lee C-Y (2011) Exploring problem solving patterns and their impact on learning achievement in a blended learning environment. Computers \& Education 56(1): 138-145.

Yen S-C, Lo Y, Lee A, et al. (2018) Learning online, offline, and in-between: Comparing student academic outcomes and course satisfaction in face-to-face, online, and blended teaching modalities. Education and Information Technologies 23(5): 2141-2153.

\section{Funding}

This research did not receive any specific grant from funding agencies in the public, commercial, or notfor-profit sectors. 
Table 1. Module 2 topics and tasks.

\begin{tabular}{|l|l|l|}
\hline Topic & Description & Student Tasks (Share own and respond to others) \\
\hline One & $\begin{array}{l}\text { Introduce to professional } \\
\text { learning network (PLN) } \\
\text { concepts }\end{array}$ & $\begin{array}{l}\text { Reflect on PLN benefits } \\
\text { Visual representation (e.g. mind map) of own current PLN } \\
\text { Main learnings and takeaways from this topic }\end{array}$ \\
\hline Two & $\begin{array}{l}\text { Explore the benefits of } \\
\text { PLNs }\end{array}$ & $\begin{array}{l}\text { Reflect on the diversity of own PLN } \\
\text { Convey dynamism of own PLN (e.g. meme) } \\
\text { Audio reflection about depth of own PLN } \\
\text { Visual representation (e.g. motivational poster) of a } \\
\text { SMART goal related to PLN }\end{array}$ \\
\hline Three & $\begin{array}{l}\text { Why and how to connect } \\
\text { and expand own PLN }\end{array}$ & $\begin{array}{l}\text { Image and meme about the importance of connections } \\
\text { within PLNs } \\
\text { Join two new spaces (e.g. Twitter) } \\
\text { Reflect on creating a new connection with someone such } \\
\text { as an educational professional }\end{array}$ \\
\hline Four & Levels of PLN participation & $\begin{array}{l}\text { Personal survey about being a turtle, fox, penguin, or tiger } \\
\text { Reflect on ideas for expanding own PLN participation } \\
\text { Experiment with new levels of participation }\end{array}$ \\
\hline Five & $\begin{array}{l}\text { Reflect on own PLN } \\
\text { evolution }\end{array}$ & $\begin{array}{l}\text { Visual representation (e.g. meme or poster) about newly } \\
\text { expanded PLN } \\
\text { Reflect on how PLN has evolved } \\
\text { Develop SMART goal for ongoing real-world PLN growth }\end{array}$ \\
\hline
\end{tabular}

Table 2: Analytical framework

\begin{tabular}{|c|c|c|}
\hline $\begin{array}{l}\text { Gunawardena's } \\
\text { model }\end{array}$ & Guiding parameters & ICAP framework \\
\hline $\begin{array}{l}\text { 1. Comparing } \\
\text { information }\end{array}$ & $\begin{array}{l}\text { A statement of observation or opinion } \\
\text { A statement of agreement } \\
\text { Corroborating examples } \\
\text { Definition, description, identification of a } \\
\text { concept/problem }\end{array}$ & \multirow{5}{*}{$\begin{array}{l}\text { a) conversational posts } \\
\text { between two or more } \\
\text { people that is } \\
\text { constructive, ideas } \\
\text { extend beyond given } \\
\text { concepts } \\
\text { b) there is a sufficient } \\
\text { degree of turn taking }\end{array}$} \\
\hline $\begin{array}{l}\text { 2. Discovering } \\
\text { inconsistency }\end{array}$ & $\begin{array}{l}\text { Identifying and stating areas of disagreement } \\
\text { Asking and answering questions to clarify } \\
\text { Restarting position and possibly advancing } \\
\text { arguments or considerations }\end{array}$ & \\
\hline $\begin{array}{l}\text { 3. Negotiating } \\
\text { ideas }\end{array}$ & $\begin{array}{l}\text { Negotiating or clarifying meaning of concepts } \\
\text { Negotiating relative weight to be assigned } \\
\text { Identification of areas of agreement or overlap } \\
\text { Proposal and negotiation of new statements } \\
\text { evidencing compromise } \\
\text { Accommodating metaphors or analogies }\end{array}$ & \\
\hline $\begin{array}{l}\text { 4. Testing of co- } \\
\text { construction with } \\
\text { evidence }\end{array}$ & $\begin{array}{l}\text { Testing the proposed ideal or concept } \\
\text { Testing against existing concepts } \\
\text { Testing against personal experience } \\
\text { Testing against formal data collected }\end{array}$ & \\
\hline $\begin{array}{l}\text { 5. Application of } \\
\text { new idea. }\end{array}$ & $\begin{array}{l}\text { Summarising of agreement } \\
\text { Application of new knowledge } \\
\text { Illustration of a new way of thinking }\end{array}$ & \\
\hline
\end{tabular}


Table 3. Module 1 number of posts and students across three participation types.

\begin{tabular}{|l|l|l|}
\hline Participation Type & Number of Posts & $\begin{array}{l}\text { Number of } \\
\text { Students }\end{array}$ \\
\hline $\begin{array}{l}\text { Background } \\
\text { participation }\end{array}$ & $129(45.9 \%)$ & $122(67.4 \%)$ \\
\hline Engaging with content & $126(44.8 \%)$ & $72(39.8 \%)$ \\
\hline Generating content & $26(9.3 \%)$ & $22(12.2 \%)$ \\
\hline Total & $281(100.0)$ & $124(68.5 \%)$ \\
\hline
\end{tabular}

Table 4. Six categories to represent complexity of observed student engagement.

\begin{tabular}{|l|l|}
\hline Label & Complexity of Engagement \\
\hline Lurk & View the content without actively participating \\
\hline Superficial & Reply to another person's post, simply liking or agreeing with that post \\
\hline Task & Complete an assigned task, posting it to Teams for other students to see \\
\hline Respond & Reply to another person's post, making a contributing comment \\
\hline Expand & $\begin{array}{l}\text { Reply to another person's post to expand the concept or idea such as seeking } \\
\text { clarification or giving feedback about own experience or perception }\end{array}$ \\
\hline Create & Start a new idea that goes above and beyond the scope of the prompted task \\
\hline
\end{tabular}

Table 5. Module 2 participation.

\begin{tabular}{|c|c|c|c|c|c|c|c|c|c|c|c|c|c|c|c|}
\hline \multirow{5}{*}{\begin{tabular}{|l|} 
Topic \\
\\
Topic \\
1
\end{tabular}} & \multirow{3}{*}{\begin{tabular}{|l|} 
Measure \\
Students \\
Engagements
\end{tabular}} & \multicolumn{2}{|c|}{ Lurk } & \multicolumn{2}{|c|}{ Superficial } & \multicolumn{2}{|c|}{ Task } & \multicolumn{2}{|c|}{ Respond } & \multicolumn{2}{|c|}{ Expand } & \multicolumn{2}{|c|}{ Create } & \multicolumn{2}{|c|}{$\begin{array}{c}\text { Total Active } \\
\text { (More than } \\
\text { lurked) }\end{array}$} \\
\hline & & & $6.6 \%$ & & $\begin{array}{r}38.7 \\
\%\end{array}$ & 163 & $\begin{array}{r}90.1 \\
\%\end{array}$ & & $\begin{array}{r}48.6 \\
\%\end{array}$ & & $\begin{array}{r}14.4 \\
\%\end{array}$ & & $\begin{array}{r}0.0 \\
\%\end{array}$ & 164 & $90.6 \%$ \\
\hline & & 0 & $0.0 \%$ & 162 & $\begin{array}{r}38.7 \\
\%\end{array}$ & 426 & $\begin{array}{r}53.9 \\
\%\end{array}$ & 164 & $\begin{array}{r}20.8 \\
\%\end{array}$ & 38 & $\begin{array}{r}4.8 \\
\%\end{array}$ & 0 & $\begin{array}{r}0.0 \\
\%\end{array}$ & 790 & $100.0 \%$ \\
\hline & Mean & & & 2.3 & & 2.6 & & 1.9 & & 1.5 & & 0 & & 4.8 & \\
\hline & $\begin{array}{l}\text { Range per } \\
\text { student }\end{array}$ & & & $0-14$ & & $0-5$ & & $0-5$ & & $0-4$ & & 0 & & $0-21$ & \\
\hline \multirow{4}{*}{$\begin{array}{l}\text { Topic } \\
2\end{array}$} & Students & 15 & $8.3 \%$ & & $\begin{array}{r}44.8 \\
\%\end{array}$ & 157 & $\begin{array}{r}86.7 \\
\%\end{array}$ & 62 & $\begin{array}{r}34.3 \\
\%\end{array}$ & 21 & $\begin{array}{r}11.6 \\
\%\end{array}$ & & $\begin{array}{r}0.6 \\
\%\end{array}$ & 176 & $97.2 \%$ \\
\hline & Engagements & 0 & $0.0 \%$ & 238 & $\begin{array}{r}29.4 \\
\%\end{array}$ & 428 & $\begin{array}{r}62.9 \\
\%\end{array}$ & 112 & $\begin{array}{r}13.8 \\
\%\end{array}$ & 31 & $\begin{array}{r}11.6 \\
\%\end{array}$ & 1 & $\begin{array}{r}0.0 \\
\%\end{array}$ & 809 & $100.0 \%$ \\
\hline & Mean & & & 2.9 & & 2.7 & & 1.8 & & 1.5 & & 0 & & 4.7 & \\
\hline & $\begin{array}{l}\text { Range per } \\
\text { student }\end{array}$ & & & $0-14$ & & $0-7$ & & $0-4$ & & $0-7$ & & I & & $0-21$ & \\
\hline \multirow{4}{*}{$\begin{array}{l}\text { Topic } \\
3\end{array}$} & Students & & $11.6 \%$ & 104 & $\begin{array}{r}57.5 \\
\%\end{array}$ & 143 & $\begin{array}{r}79.0 \\
\%\end{array}$ & 62 & $\begin{array}{r}34.3 \\
\%\end{array}$ & 18 & $\begin{array}{r}9.9 \\
\%\end{array}$ & 0 & $\begin{array}{r}0.0 \\
\%\end{array}$ & 155 & $85.6 \%$ \\
\hline & Engagements & 0 & $0.0 \%$ & 278 & $\begin{array}{r}39.3 \\
\%\end{array}$ & 318 & $\begin{array}{r}44.9 \\
\%\end{array}$ & 92 & $\begin{array}{r}13.0 \\
\%\end{array}$ & 20 & $\begin{array}{r}2.8 \\
\%\end{array}$ & 0 & $\begin{array}{r}0.0 \\
\%\end{array}$ & 708 & $100.0 \%$ \\
\hline & Mean & & & 2.7 & & 2.2 & & 1.5 & & 1.1 & & 0 & & 4.6 & \\
\hline & $\begin{array}{l}\text { Range per } \\
\text { student }\end{array}$ & & & $0-11$ & & $0-4$ & & $0-4$ & & $0-2$ & & 0 & & $0-16$ & \\
\hline \multirow{4}{*}{$\begin{array}{l}\text { Topic } \\
4\end{array}$} & Students & 27 & $14.9 \%$ & 66 & $\begin{array}{r}36.5 \\
\%\end{array}$ & 139 & $\begin{array}{r}76.8 \\
\%\end{array}$ & 86 & $\begin{array}{r}47.5 \\
\%\end{array}$ & 29 & $\begin{array}{r}16.0 \\
\%\end{array}$ & 1 & $\begin{array}{r}0.6 \\
\%\end{array}$ & 149 & $82.3 \%$ \\
\hline & Engagements & 0 & $0.0 \%$ & 141 & $\begin{array}{r}25.4 \\
\%\end{array}$ & 228 & $\begin{array}{r}41.0 \\
\%\end{array}$ & 138 & $\begin{array}{r}24.8 \\
\%\end{array}$ & 49 & $\begin{array}{r}8.8 \\
\%\end{array}$ & & $\begin{array}{r}0.0 \\
\%\end{array}$ & 556 & $100.0 \%$ \\
\hline & Mean & & & 2.1 & & 1.6 & & 1.6 & & 1.7 & & 0 & & 3.7 & \\
\hline & $\begin{array}{l}\text { Range per } \\
\text { student }\end{array}$ & & & $0-12$ & & $0-4$ & & $0-5$ & & $0-4$ & & $\begin{array}{c}0- \\
1\end{array}$ & & $0-18$ & \\
\hline
\end{tabular}

Page 13 of 17 


\begin{tabular}{|c|c|c|c|c|c|c|c|c|c|c|c|c|c|c|c|}
\hline \multirow{4}{*}{$\begin{array}{l}\text { Topic } \\
5\end{array}$} & Students & & $29.8 \%$ & 67 & $\begin{array}{r}37.0 \\
\%\end{array}$ & 114 & $\begin{array}{r}63.0 \\
\%\end{array}$ & 73 & $\begin{array}{r}40.3 \\
\%\end{array}$ & 32 & $\begin{array}{r}17.7 \\
\%\end{array}$ & 0 & $\begin{array}{r}0.0 \\
\%\end{array}$ & 122 & $67.4 \%$ \\
\hline & Engagements & 0 & $0.0 \%$ & 268 & $\begin{array}{r}37.8 \\
\%\end{array}$ & 205 & $\begin{array}{r}28.9 \\
\%\end{array}$ & 178 & $\begin{array}{r}25.1 \\
\%\end{array}$ & 58 & $\begin{array}{r}8.2 \\
\%\end{array}$ & 0 & $\begin{array}{r}0.0 \\
\%\end{array}$ & 709 & $100.0 \%$ \\
\hline & Mean & & & 4.0 & & 1.8 & & 2.4 & & 1.8 & & $\begin{array}{l}0 . \\
0\end{array}$ & & 5.8 & \\
\hline & $\begin{array}{l}\text { Range per } \\
\text { student }\end{array}$ & & & $0-18$ & & $0-3$ & & $\begin{array}{l}0- \\
11\end{array}$ & & $0-4$ & & 0 & & $0-32$ & \\
\hline \multirow{4}{*}{ Total } & Students & 5 & $2.8 \%$ & 141 & $\begin{array}{r}77.9 \\
\%\end{array}$ & 169 & $\begin{array}{r}93.4 \\
\%\end{array}$ & 135 & $\begin{array}{r}74.6 \\
\%\end{array}$ & 78 & $\begin{array}{r}43.1 \\
\%\end{array}$ & 2 & $\begin{array}{r}1.1 \\
\%\end{array}$ & 176 & $97.2 \%$ \\
\hline & Engagements & & & $\begin{array}{r}1,08 \\
7\end{array}$ & $\begin{array}{r}30.4 \\
\%\end{array}$ & $\begin{array}{r}1,60 \\
5\end{array}$ & $\begin{array}{r}44.9 \\
\%\end{array}$ & 684 & $\begin{array}{r}19.1 \\
\%\end{array}$ & 196 & $\begin{array}{r}5.5 \\
\%\end{array}$ & 2 & $\begin{array}{r}0.0 \\
\%\end{array}$ & $\begin{array}{r}3,57 \\
4\end{array}$ & $100.0 \%$ \\
\hline & Mean & & & 7.7 & & 9.5 & & 5.1 & & 2.5 & & $\begin{array}{l}1 . \\
0\end{array}$ & & 20.3 & \\
\hline & $\begin{array}{l}\text { Range per } \\
\text { student }\end{array}$ & & & $0-62$ & & $0-17$ & & $\begin{array}{l}0- \\
21\end{array}$ & & $\begin{array}{c}0- \\
11\end{array}$ & & $\begin{array}{r}0- \\
1\end{array}$ & & $0-97$ & \\
\hline
\end{tabular}

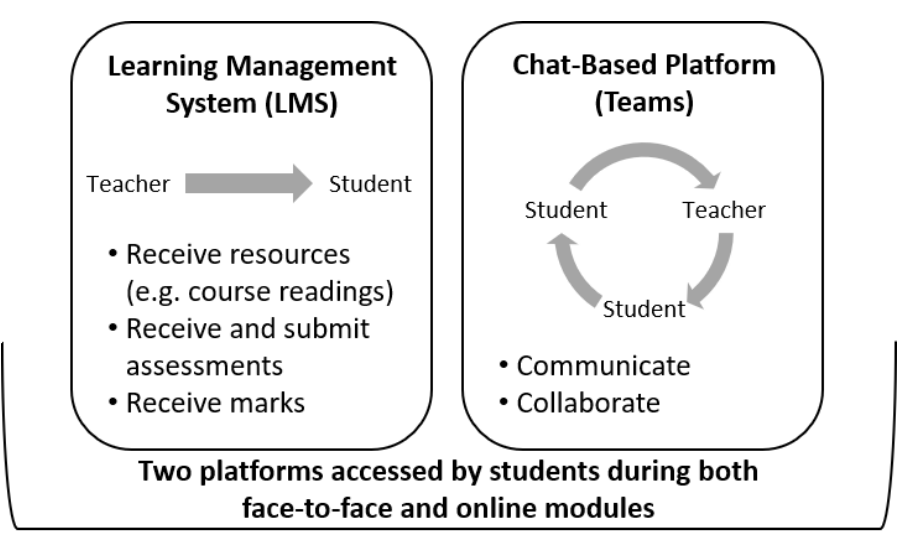

Figure 1. Two digital teaching and learning platforms were used.

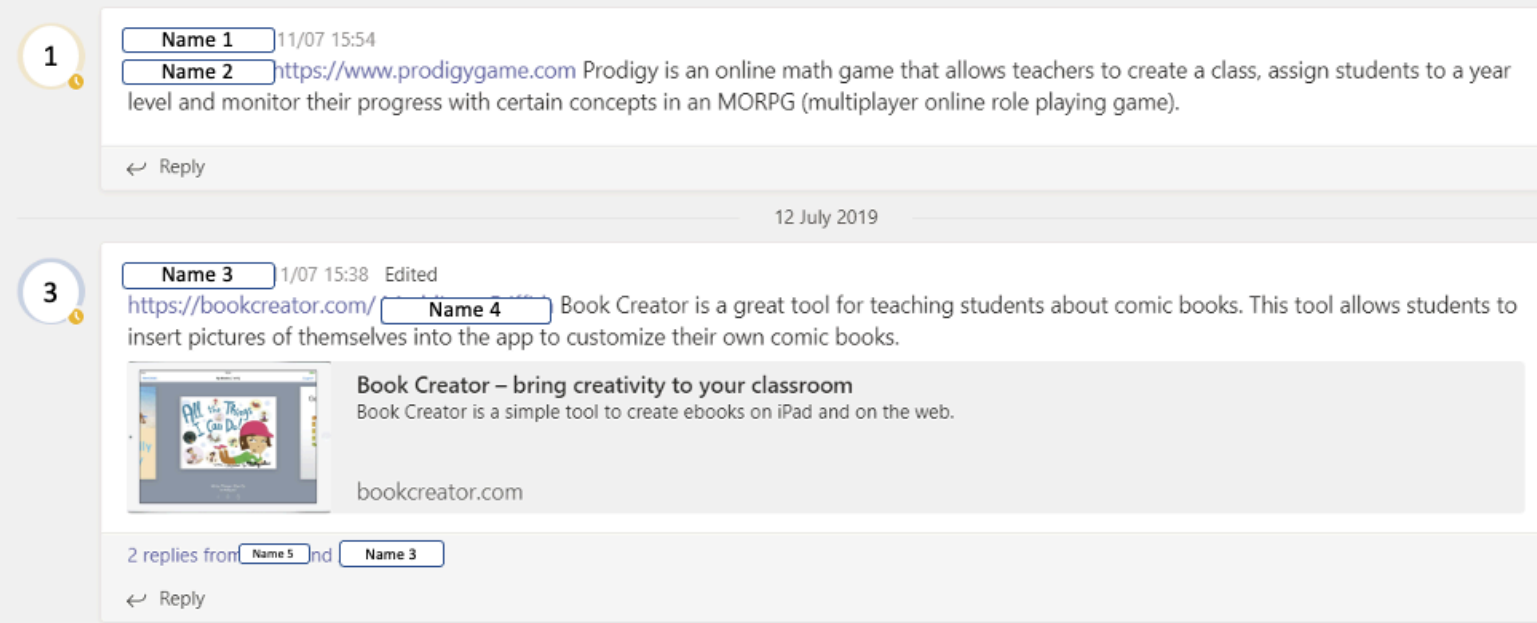

Figure 2. Example 'generating content' participation. 


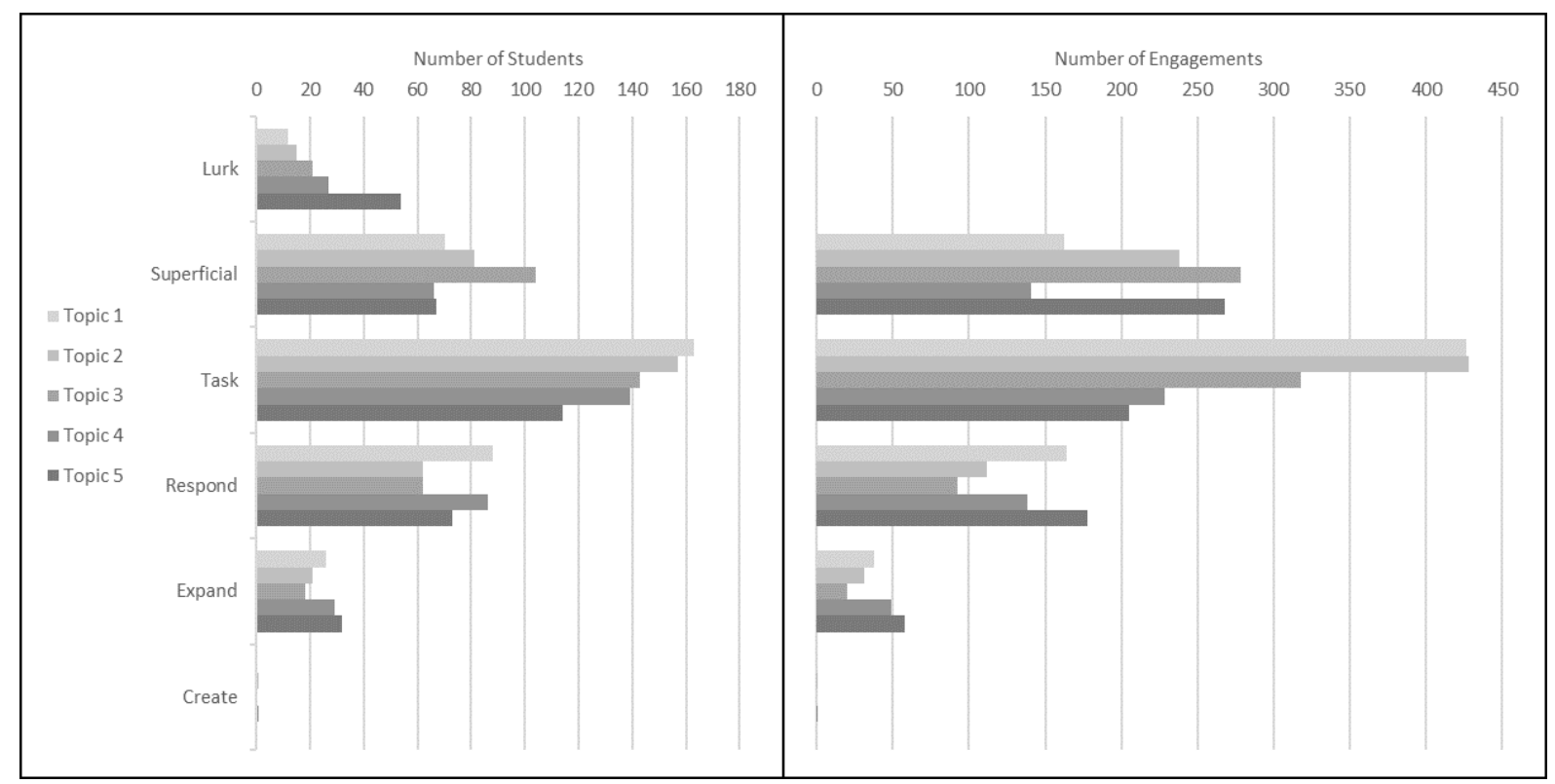

Figure 3. Number of students and number of engagements by complexity of engagement across five learning topics in Module 2.

\section{1 \\ Name 1 10:14 \\ 1.5 Which PLN Benefits Are Relevant to You?}

As a pre-service teacher, I believe the affective benefits are relevant to me. Having a Professional Learning Network that will emotionally support me along this learning journey will have great benefits as sometimes I do get stuck and need to reach out to someone for assistance, especially when on placement. Having this support from a large amount of people, such as from the online space, will help me to feel more confident and reassured, as I will be able to take more risks and be more open to learning and trying new teaching strategies that might be out of my comfort zone. This will not only help my future students, but also help me to progress my journey as a lifelong learner.

See less

- Collapse all

2 Name 2 01/09 23:05 I totally agree with you Name 1 is nice to know that there are actually things like this out there waiting for us. I know I will definitely appreciate the support, and the opportunities to learn from others. I hope that I can contribute something that helps someone else.

3 Name $30^{02 / 09} 11: 25$

me. I get overwhelmed and it really does help to reach out to your peers for support.

$4 \quad$ Name 4 02/09 15:14

You're so right! I did not think of this perspective when writing my response. Having the support of others in the same situation makes it a little easier to push through during difficult times.

$\leftarrow$ Reply

Figure 4. Example 'respond' type engagement demonstrating joint dialogue. 
1

Name 1 Written Reflection: Examining PLN Benefits:

As a pre-service teacher the affective benefits resonate with me as I feel that many times I do not think I have enough knowledge or professional experience and this has led me to second-guessing myself, and the lessons I have created. Having affective support from a colleague would help me become more confident in taking risks in the classroom, like integrating more ICT's and experimenting with a range See more

Collapse all

2

Name 2 28/08 15:29 Edited

Sometimes I get this feeling when delivering a lesson too but the teacher will see it differently. With a PLN I feel we can start having that belief in ourselves that what we are doing with what we have is promoting the learning and development of our students. Knowing we have the support from other educators, colleagues and previous teachers of our own will really help us to have the confidence in trying new things.

3) So true Name 1 and Name 2 I think PLNs are great in the way that they can show us what we are already doing effectively and also alerting us to aspects of our pedagogy that we need to improve, with the support of a community of like-minded people.

$\leftarrow$ Reply

Figure 5. Example 'expand' type engagement demonstrating joint dialogue.

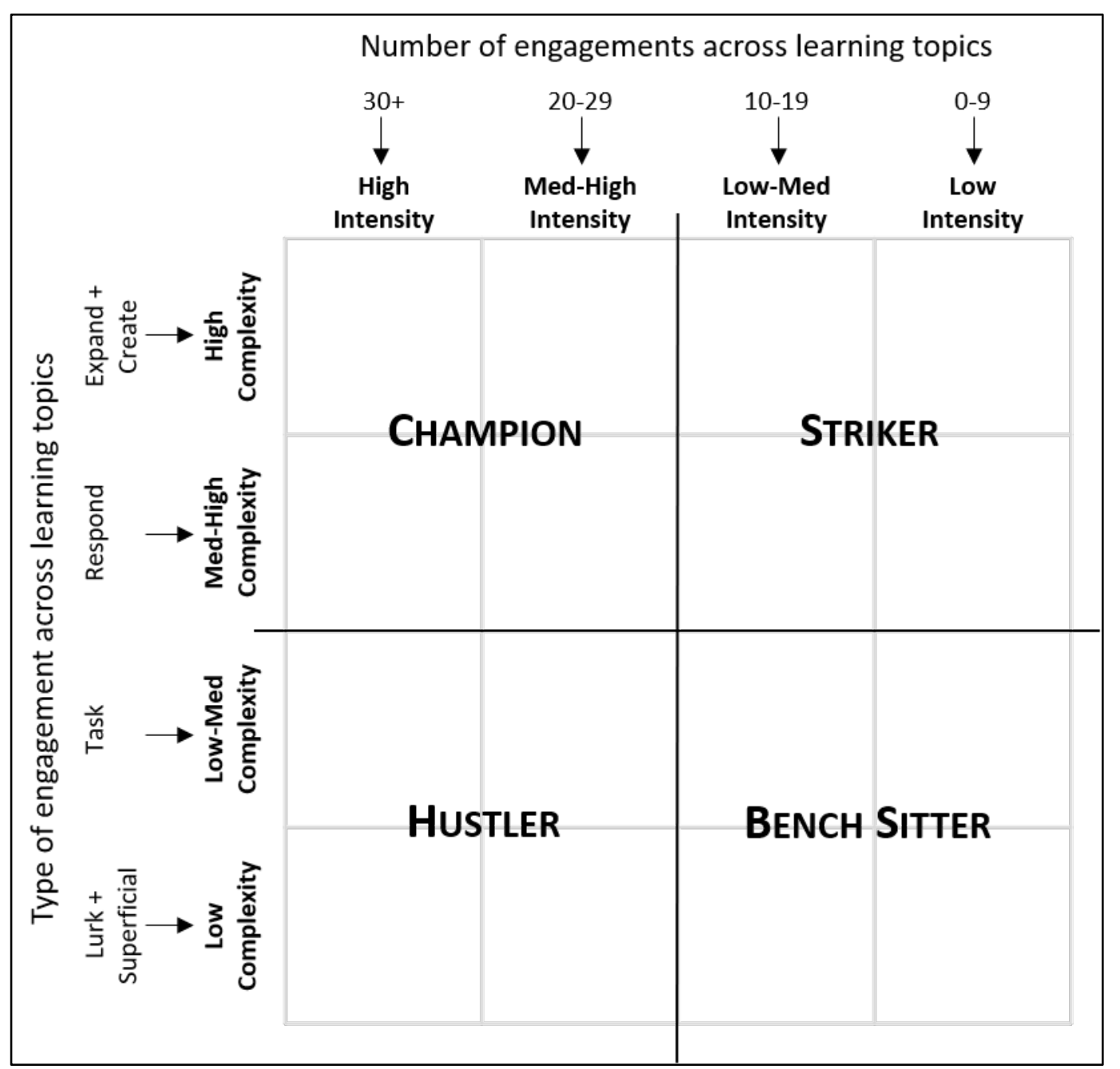

Figure 6. Transforming type and number of engagements into a typology of chat-based student engagement. 
Hey guys, in the chat a lot of people said they use Instagram to engage in online PLN's.

Comment below some pages that you love so we can all share and expand our PLN's!

- Collapse all

1

Name 1 04/09 10:3?

favourite page to follow is @teacherishappy

She uses some amazing resources and she gives some helpful tips for new teachers!

2 Name 2

(1) teacherishappy,@missgirlingsclassroom,@missteacher2be, @yearthreeshenanigans @giftedandtalentedteacher, (a)theyoungeducator

3 Name 3 04/09 10:47

@play.and.learn.activities, @giftedandtalentedteacher, @talesfrommissd, @stayclassyclassrooms

Also I follow a lot of broader professionals on things like sensory play and Montessori I find these interesting and inspiring in how to implement them even into my own practises: @montessoriinreallife, @imaginationtree

4 Name 4 05/09 13:25

@miss fairclough, @primarily_mrs.e, @outbackteacher, @remoteteacher, @teaandcountryteaching, @teachingblack,

5 Name 5 05/09 18:49

Crowd sourcing ideas! Very clever :]

1 Name 1 19/09 16:1 Name 6 here is the post I was mentioning, I hope you can find some page you may like, to expand your PLN $\because$ $\hookleftarrow$ Reply

Figure 7. Example student profiled as having Champion engagement.

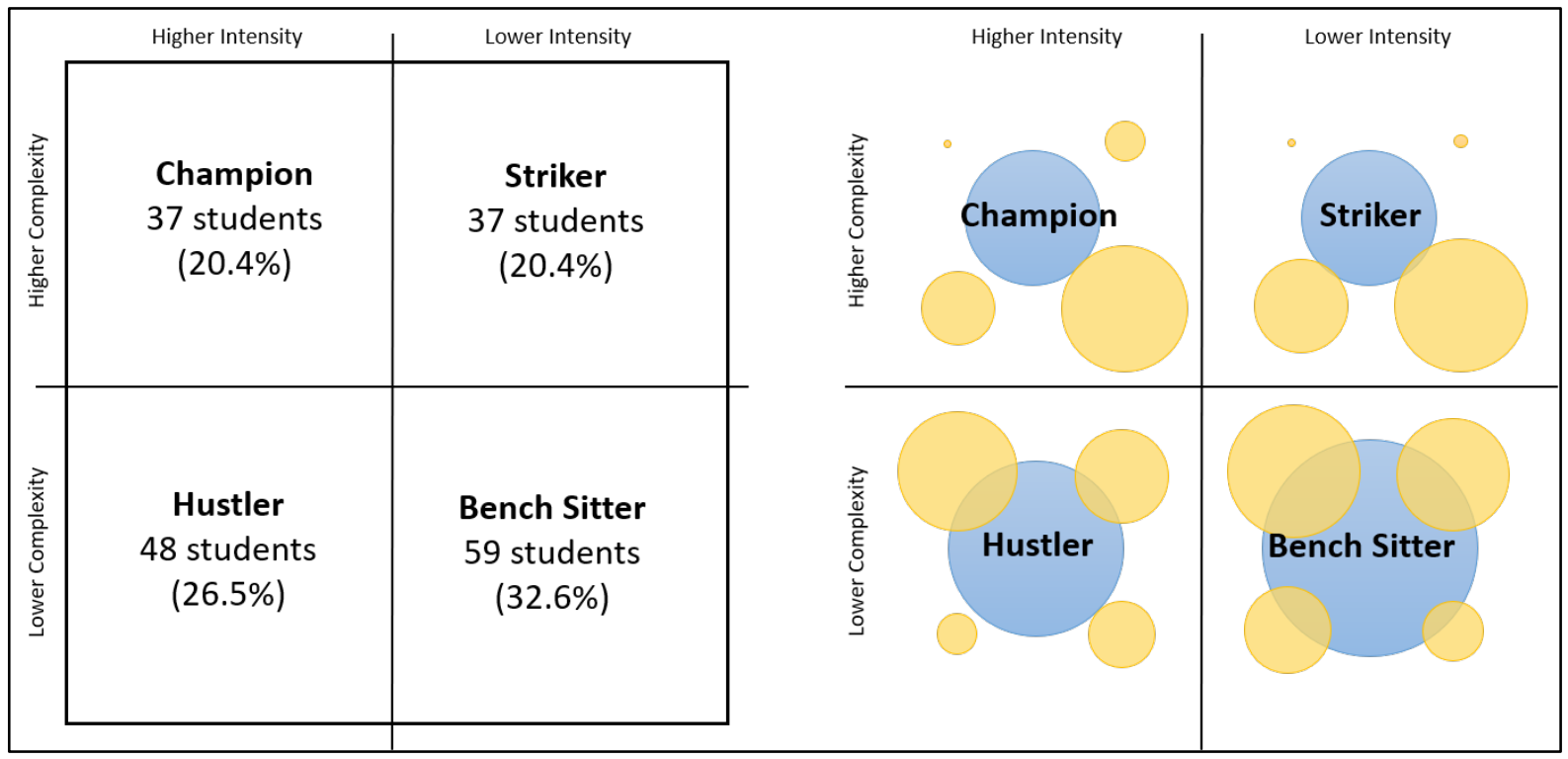

Figure 8. Final engagement profiles of 181 students. 